\title{
BENEFITS OF INSULIN ASPART VS PHOSPHATE-BUFFERED HUMAN REGULAR INSULIN IN PERSONS WITH TYPE 1 DIABETES TREATED BY MEANS OF AN INSULIN PUMP
}

\author{
Rudolf Chlup ${ }^{a^{*}}$, Jana Zapletalová ${ }^{b}$, Pavel Sečkař ${ }^{c}$, Ludmila Chlupová ${ }^{\text {, }}$, Svatava Táncosováe, \\ Martina Řzníčkováa
}

\author{
a Institute of Physiology and IInd Department of Medicine, Palacký University \& Hospital, 775 20 Olomouc, Czech Republic; \\ e-mail rudolf.chlup@fnol.cz \\ b Department of Biometrics, Faculty of Medicine, Palacký University, Olomouc \\ c Department of Health Insurance, Teaching Hospital, Olomouc \\ d Department of Special Education, Faculty of Paedagogics, Palacký University, Olomouc \\ e Institute of Neurology and Geriatrics, Moravský Beroun
}

Received: April 28, 2004; Accepted: May 30, 2004

Key words: Diabetes mellitus/Insulin pump/Insulin aspart/Selfmonitoring/Glucometer

Absorption rates of phosphate buffered insulin analogs aspart and lispro prevail over regular human insulin. However, insulin aspart has not been widely used. The aim of this open controlled clinical study is to compare the metabolic effects of insulin aspart and phosphate buffered insulin when both are used in insulin pumps according to the identical algorithms. Methods: Twenty one persons aged $39.9 \pm 2.89$ (mean \pm SE) years (y) with type 1 diabetes mellitus duration of $17.9 \pm 2.21 \mathrm{y}$ treated by an insulin pump for $4.3 \pm 0.53 \mathrm{y}$ (at least 3 months), educated in selfmonitoring, entered the study. Mean plasma glucose, rates of hypo- and hyperglycaemias from the glucometer memory and other data from the first $256 \pm 19.97$ days period with regular human insulin (check-up 1 and 2) and consequent $364 \pm 8.78$ days long period with insulin aspart (check-up 3 and 4) were compared (paired t-test). Replacement of human regular insulin with insulin aspart after two check-ups was the only change in the treatment of diabetes. No special therapeutic education or training was made during the study. Results: In persons with type 1 diabetes treated by an insulin pump with insulin aspart, despite the lower daily dose of insulin aspart vs human regular insulin, the HbA1c decreased; the frequency of hypo- and hyperglycaemias and the BMI did not change. Conclusions: Insulin analog aspart appears to be more effective for continuous subcutaneous insulin infusion than regular human insulin.

\section{INTRODUCTION}

Absorption rates of the phosphate buffered insulin analogs aspart (Novorapid, Novo Nordisk) and lispro (Humalog, Eli Lilly) prevail over regular human insu$\operatorname{lin}^{6,8,11,13}$. Due to their monomeric structure they are absorbed from the subcutaneous tissue immediately after application, whereas the hexameric form of regular insulin needs to be split into absorbable monomers first. For this reason the absorbtion of regular human insulin takes about 10-20 min longer. Since the beginning of the insulin pump era in the year $1978^{10}$, various kinds of shortacting insulin have been used for continuous subcutaneous insulin infusion. Phosphate buffered human insulin (Velosulin HM, Novo Nordisk) was recommended because of its low aggregability in tubing systems. In recent years good effects of insulin lispro applied in continuous subcutaneous insulin infusion have been described ${ }^{9,12}$. There was also some positive experience with insulin aspart ${ }^{2-5}$. However, insulin aspart has not been widely used. The distribution of Novorapid in the Czech Republic started as late as in Octobre 2002.

\section{AIMS}

The aim of this open controlled clinical study is to compare the effects of insulin aspart and phosphate buffered regular human insulin when both are used in insulin pumps according to identical algorithms:

1. on parameters of carbohydrate metabolism (P-glucose, HbAlc, S-fructosamine);

2. on parameters of lipoprotein metabolism (S-cholesterol, S-HDL-, S-LDL-cholesterol and S-triacylglycerols);

3. on clinical parameters (body mass index, blood pressure and heart rate);

4. on other biochemical parameters of mineral metabolism, liver and kidney function;

5. on patients' satisfaction.

\section{MATERIAL AND METHODS}

\section{Persons with type 1 diabetes mellitus}

Twenty one persons with type 1 diabetes mellitus treated by means of an insulin pump for least 3 months, educated 
in selfmonitoring (SM) on glucometer Optium, Abbott/ Medisense, and attending routine medical check-ups at 1- to 2- month intervals, completed the study (Table 1).

\section{Study design}

This trial was performed in the period from January 2002 till March 2004 according to the followinng schedule:

1. At the end of the year 2002 (within several weeks after the registration of insulin Novorapid in the Czech Republic), all persons with diabetes treated with phosphate buffered regular human insulin (Velosulin HM) by means of an insulin pump in our out-patient department $(n=21)$ received a brief information from his physician about the existence of a new kind of insulin preparation (Novorapid) and they agreed to use this insulin in the next treatment.

2. In each person, clinical and laboratory data from their two routine check-ups in the year 2002 (when only Velosulin HM was used for their insulin treatment), i.e., from the first check-up in 2002 (the study checkup 1) and from the last check-up before the insulin change (the study check-up 2) were registered in the study protocol.

3. Everyone was encouraged to fulfill six steps:

- to carry out one P-glucose profile consisting of 10 P-glucose estimations (6:00, 9:00, 12:00, 15:00, $17: 30,20.30,22: 00,0: 30,2: 30,6: 00 \mathrm{~h})$ on glucometer Optium;

- to begin the treatment with Novorapid instead of Velosulin HM;

- to repeat the ten-point P-glucose profile within one month after the change;
- to continue his/her usual life style including food, exercise, frequent selfmonitoring;

- to keep to the same basal rate and to use the same algorithms for the adaptation of preprandial insulin boluses;

- to contact his/her physician when necessary (as usual).

4. Treatment of concomitant disorders such as hyperlipoproteinaemia, hypertension, renal insuficiency, ischaemic heart disease etc. (see Table 1) continued as before, according to usual principles.

5. Data from two check-ups with insulin Novorapid, i.e. from a check-up about three month after the insulin change (the study check-up 3 ) and from a check-up about one year after the change (the study check-up 4), were registered in the study protocol.

6. Mean plasma glucose (MPG) and rates of hypo- and hyperglycaemias in the course of the 2-month period before the respective check-up were assessed from glucometer memory.

7. At the check-up 3 and 4 everyone was asked whether he/she would prefer to switch back to Velosulin HM or to go on with Novorapid and the number of local complications resulting from pump therapy was sumarized.

\section{Statistical evaluation}

Clinical and laboratory data from the first period with regular human insulin Velosulin HM (check-up 1 and 2) and the consequent period with insulin aspart Novorapid (check-up 3 and 4) were compared. Correlations between $\mathrm{HbA1c}$ vs. total daily insulin dose and HbA1c vs. frequency of selfmonitoring were sought.

Table 1. Characteristics of persons with type 1 diabetes in the study (n or mean \pm SE).

\begin{tabular}{|l|l|}
\hline Parameter & Data \\
\hline $\mathrm{n}$ & 21 \\
\hline men/women [n] & $9 / 12$ \\
\hline age [years] & $39.9 \pm 2.89$ \\
\hline duration of diabetes [years] & $17.9 \pm 2.21$ \\
\hline neuropathy [n] & 11 \\
\hline retinopathy [n] & 6 \\
\hline nephropathy [n] & 5 \\
\hline dyslipoproteinaemia & 8 \\
\hline hypertension & 4 \\
\hline coronary artery disease (CABG) & 1 \\
\hline renal insuficiency/CAPD & $2 / 1$ \\
\hline gastritis & 1 \\
\hline focal nodular hyperplasia (liver) & 1 \\
\hline duration of insulin pump therapy [years] & $4.3 \pm 0.53$ \\
\hline number of pumps Minimed, Medtronic[n] & 18 \\
\hline number of pumps H-tron, Disetronic [n] & 3 \\
\hline type of the catheter & Silhouette, Minimed-Medtronic \\
\hline
\end{tabular}

CABG - coronary artery bypass grafting, CAPD - continuous ambulatory peritoneal dialysis 
Table 2. Control of type 1 diabetes mellitus with human regular insulin (Velosulin HM) and with insulin aspart

(Novorapid) administered by means of an insulin pump (mean $\pm \mathrm{SE}$ ).

\begin{tabular}{|c|c|c|c|c|}
\hline Insulin & Velosulin HM & Velosulin HM & Novorapid & Novorapid \\
\hline Check-up & 1 & 2 & 3 & 4 \\
\hline No of days from the change & $-256 \pm 19.97$ & $-18 \pm 4.91$ & $+80 \pm 7.05$ & $+364 \pm 8.78$ \\
\hline Body mass $[\mathrm{kg}]$ & $68.0 \pm 2.55$ & $68.9 \pm 2.7$ & $69.4 \pm 2.76$ & $69.5 \pm 2.84$ \\
\hline BMI $\left[\mathrm{kg} / \mathrm{m}^{2}\right]$ & $23.2 \pm 0.66$ & $23.4 \pm 0.75$ & $23.7 \pm 0.79$ & $23.7 \pm 0.81$ \\
\hline Blood pressure syst. [mm Hg] & $125.4 \pm 1.91$ & $123.4 \pm 2.03$ & $130.2 \pm 4.48$ & $123.9 \pm 2.56$ \\
\hline Blood pressure diast. [mm Hg] & $80.2 \pm 1.22$ & $77.4 \pm 1.89$ & $81.4 \pm 3.09$ & $79.0 \pm 2.19$ \\
\hline Heart rate $\left[\mathrm{min}^{-1}\right]$ & $72.6 \pm 1.11$ & $76.6 \pm 1.89$ & $74.2 \pm 1.39$ & $76.3 \pm 2.00$ \\
\hline Frequency of SM/d (Optimum) & & $3.1 \pm 0.21$ & $4.0 \pm 0.43^{*}$ & $3.0 \pm 0.25$ \\
\hline MPG (Optium)[mmol/1] & & $10.0 \pm 0.40$ & $9.5 \pm 0.39$ & $9.8 \pm 0.38$ \\
\hline $\mathrm{PG}<4$ mmol/1 (Optium) [\%] & & $8.9 \pm 1.24$ & $10.7 \pm 1.77$ & $10.8 \pm 1.41$ \\
\hline PG > $10 \mathrm{mmol} / 1$ (Optium) [\%] & & $44.9 \pm 3.72$ & $40.7 \pm 3.12$ & $42.5 \pm 3.54$ \\
\hline Fruktosamin $[\mu \mathrm{mol} / 1]$ & $417 \pm 17.44$ & $415.0 \pm 17.64$ & $377.1 \pm 13.99 *$ & $406.8 \pm 24.87$ \\
\hline Cholesterol [mmol/1] & $4.9 \pm 0.17$ & $4.8 \pm 0.19$ & $4.6 \pm 0.17$ & $4.6 \pm 0.18$ \\
\hline Triacylglycerols [mmol/1] & $1.2 \pm 0.13$ & $1.1 \pm 0.15$ & $1.3 \pm 0.19$ & $1.1 \pm 0.11$ \\
\hline LDL-cholesterol [mmol/1] & $2.6 \pm 0.16$ & $2.4 \pm 0.18$ & $2.4 \pm 0.19$ & $2.4 \pm 0.16$ \\
\hline HDL-cholesterol [mmol/1] & $1.7 \pm 0.11$ & $1.8 \pm 0.10$ & $1.7 \pm 0.08$ & $1.7 \pm 0.09$ \\
\hline $\mathrm{K}[\mathrm{mmol} / \mathrm{l}]$ & $4.6 \pm 0.09^{*}$ & $4.4 \pm 0.1$ & $4.4 \pm 0.08$ & $4.4 \pm 0.10$ \\
\hline $\mathrm{Na}[\mathrm{mmol} / \mathrm{l}]$ & $139.2 \pm 0.94$ & $137.3 \pm 0.80$ & $137.9 \pm 0.71$ & $138.6 \pm 0.53$ \\
\hline $\mathrm{Cl}[\mathrm{mmol} / \mathrm{l}]$ & $103.8 \pm 0.77$ & $102.5 \pm 0.65$ & $103.8 \pm 0.71$ & $105.2 \pm 0.74 *$ \\
\hline $\mathrm{Ca}[\mathrm{mmol} / 1]$ & $2.4 \pm 0.04$ & $2.5 \pm 0.04$ & $2.4 \pm 0.02$ & $2.5 \pm 0.04$ \\
\hline $\mathrm{P}[\mathrm{mmol} / 1]$ & $1.1 \pm 0.06$ & $1.2 \pm 0.05$ & $1.3 \pm 0.04$ & $1.2 \pm 0.05$ \\
\hline $\mathrm{Mg}[\mathrm{mmol} / \mathrm{l}]$ & $0.9 \pm 0.02$ & $0.9 \pm 0.02$ & $0.9 \pm 0.02$ & $0.9 \pm 0.07$ \\
\hline Urea [mmol/1] & $6.6 \pm 1.2$ & $6.5 \pm 1.20$ & $6.2 \pm 0.85$ & $5.6 \pm 0.62$ \\
\hline Creatinine $[\mu \mathrm{mol} / 1]$ & $105.1 \pm 12.67$ & $100.6 \pm 12.86$ & $99.2 \pm 11.27$ & $95.0 \pm 10.00$ \\
\hline Uric acid $[\mu \mathrm{mol} / 1]$ & $237.4 \pm 17.86$ & $224.0 \pm 16.51$ & $244.6 \pm 15.49$ & $215.3 \pm 14.63$ \\
\hline Bilirubin $[[\mu \mathrm{mol} / 1]$ & $14.4 \pm 3.03 *$ & $16.2 \pm 1.86$ & $13.4 \pm 1.8 *$ & $13.6 \pm 1.55^{*}$ \\
\hline ALT [ $\mu \mathrm{kat} / 1]$ & $0.4 \pm 0.03$ & $0.4 \pm 0.03$ & $0.5 \pm 0.09$ & $0.4 \pm 0.03$ \\
\hline AST $[[\mu \mathrm{kat} / 1]$ & $0.4 \pm 0.02$ & $0.4 \pm 0.02$ & $0.4 \pm 0.06$ & $0.5 \pm 0.05$ \\
\hline ALP [[ $[\mu \mathrm{kat} / 1]$ & $1.0 \pm 0.13$ & $1.1 \pm 0.11$ & $1.2 \pm 0.09^{*}$ & $1.4 \pm 0.09^{*}$ \\
\hline GMT [[ $[\mu \mathrm{kat} / 1]$ & $0.5 \pm 0.18$ & $0.6 \pm 0.30$ & $0.7 \pm 0.38$ & $0.7 \pm 0.44$ \\
\hline Total proteins [g/1] & $74.5 \pm 1.37$ & $72.9 \pm 1.1$ & $71.8 \pm 1.31$ & $72.5 \pm 1.37$ \\
\hline Correlation $\mathrm{r}$ insulin dose vs. HbAlc & $0.50^{\mathrm{x}}$ & $0.42^{\mathrm{x}}$ & 0,31 & 0.36 \\
\hline Correlation r SM frequency vs HbAlc & & -0.42 & -0.40 & -0.26 \\
\hline
\end{tabular}

$\mathrm{n}=21 ;{ }^{*} \mathrm{p}<0.05$ vs. check-up $2 ;{ }^{\mathrm{x}} \mathrm{p}<0.05$

PC Link (Abbott/Medisense) enabled transfer of the results of selfmonitoring from glucometer Optium to a PC. MS Excel and SPSS v. 10.1 were used to analyze the data. A paired t-test was applied whenever possible. $p<0.05$ was considered to be of statistical significance.

\section{RESULTS}

Ten-point P-glucose profiles with Velosulin HM and with Novorapid are shown in Fig 1 (means) and in Fig. 2 (medians). Only the difference at 6:00 h was significant $(\mathrm{p}<0.05)$.

The HbAlc decreased within 12 month after the change to Novorapid; at check-up 4, the differences vs. check-up 1, vs. check-u 2 and vs. check-up 3 were significant (Fig. 3), even though the total daily insulin dose at 


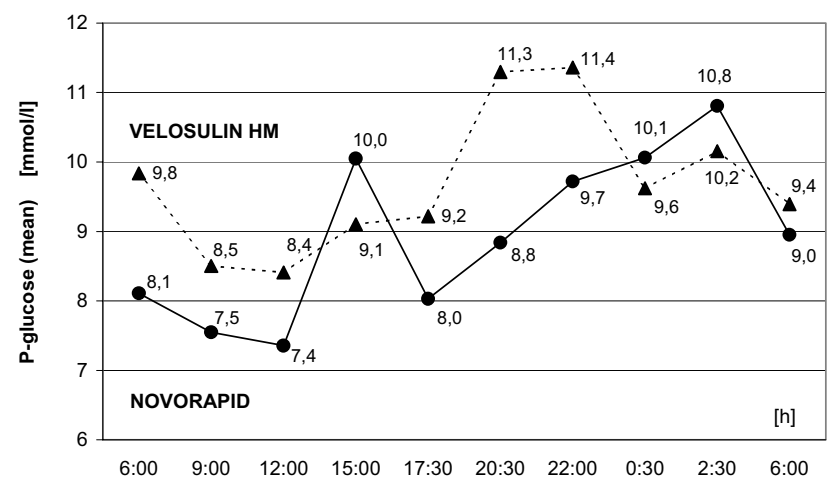

Fig. 1. Ten-point P-glucose profile with phosphate buffered human regular insulin (Velosulin HM) and with insulin aspart (Novorapid); some profiles were not complete, that's why in individual points $n$ varies: $\mathrm{n}=20,21,21,20,20,17,17,14,17,21$; means

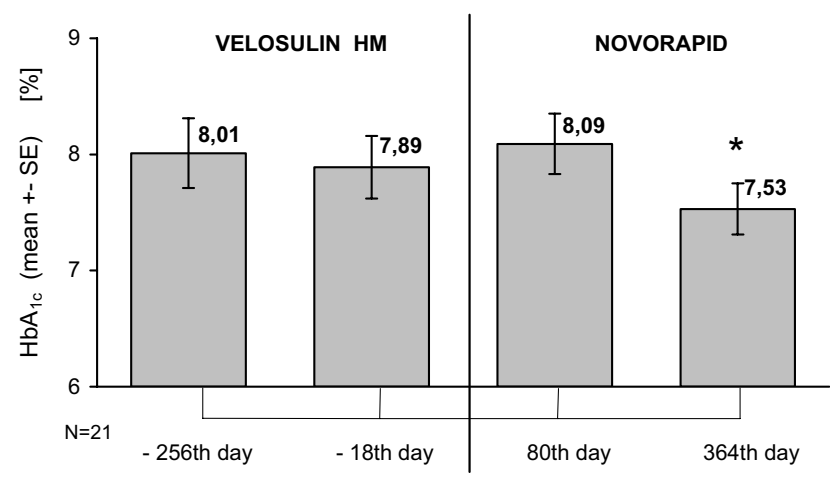

Fig. 3. HbA1c with phosphate buffered human regular insulin (Velosulin HM) and with insulin aspart (Novorapid); means $\pm \mathrm{SE} ;{ }^{*} \mathrm{p}<0.05$ vs. check-up 1, 2 and 3 ; HbA1c values are given according to the DCCT/NGSP scale (reference range 4.20-6.0\%); in order to convert these traditional NGSP values to the recent IFCC values following eqation may be used: $\mathrm{IFCC}=(\mathrm{NGSP}-2.15): 0.915[\%]$

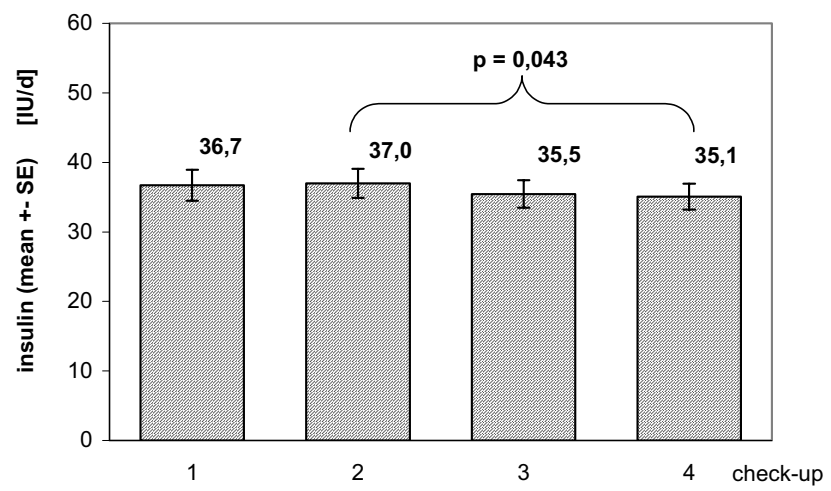

Fig. 5. Total daily insulin dose with phosphate buffered human regular insulin (Velosulin HM, check-up 1 and 2) and with insulin aspart (Novorapid, check-up 3 and 4); means $\pm \mathrm{SE}$

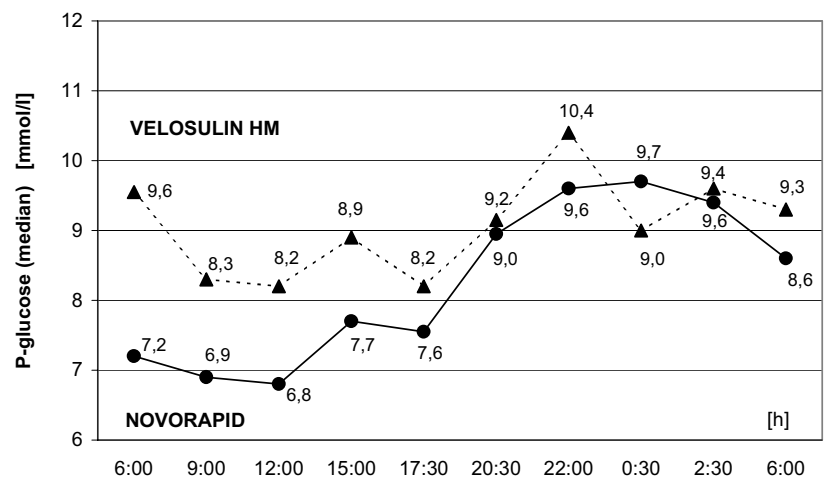

Fig. 2. Ten-point P-glucose profile with phosphate buffered human regular insulin (Velosulin HM) and with insulin aspart (Novorapid); some profiles were not complete, that's why in individual points $\mathrm{n}$ varies: $\mathrm{n}=20,21,21,20,20,17,17,14,17,21$; medians

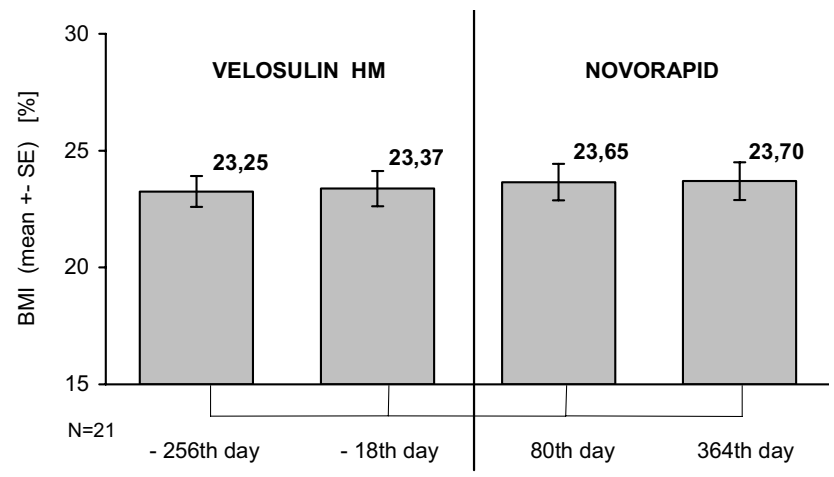

Fig. 4. Body mass index with phosphate buffered human regular insulin (Velosulin HM) and with insulin aspart (Novorapid); means $\pm \mathrm{SE}$; no significant difference

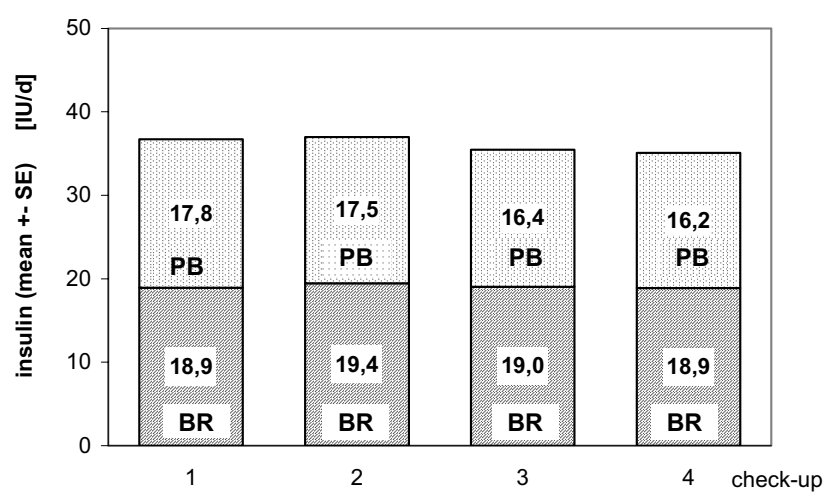

Fig. 6. Mean basal rate (BR) and prandial boluses (PB) with phosphate buffered human regular insulin (Velosulin HM) and with insulin aspart (Novorapid) 
check-up 4 vs. check-u 2 was lower (Fig. 5) as a result of to both smaller prandial boluses and smaler basal rates (Fig. 6).

The BMI did not change (Fig. 4).

There was no significant change in basal heart rate and blood pressure. Changes in laboratory parameters were exceptional (Table 2).

No strong correlation either between $\mathrm{HbAlc}$ vs. daily insulin dose or between $\mathrm{HbAlc}$ vs. frequency of selfmonitoring could be found. (Table 2).

Concerning the patients'satisfaction, at the check-up 3 only one person (with renal insuficiency) would probably prefer to switch back to Velosulin HM; namely, he felt the sensations of hypoglycaemia appeared more frequently with Novorapid. After the reduction of basal rate and prandial boluses he agreed to go on with Novorapid, as well as at the check-up 4. Fourteen patients were (since the change) undoubtedly enthusiastic with Novorapid because of better flexibility in administration of prandial boluses and generally better felt condition. Six patients would not object to go on with either Novorapid or Velosulin HM as they could not see any particular advantage in the treatment with Novorapid.

In the course of 7800 patient-days with Novorapid, there was one local infection at the site of catheter Silhouette insertion demanding surgical intervention, and some minor problems (one or two per patient per year) with tubing system Silhouette.

\section{DISCUSSION}

The results of two check-ups in the course of the first period (with Velosulin HM) may be considered as "a control group", and, as well, a stable baseline. No significant difference between the check-up 1 and 2 were found.

Replacement of phosphate buffered regular insulin (Velosulin HM) with insulin aspart (Novorapid) after check-up 2 was the only change in the treatment. The patients had no special training or therapeutic education and they were not aware that they are in a study. For this reason, there was (if any) only a little influence of the factor "improvement due to being observed" as it has been seen in some clinical studies. Hence, the significant improvement of $\mathrm{HbAlc}$ at check-up 4 by $0.48 \%$ vs. checkup 1 and by $0.36 \%$ vs. check-up 2 may be considered as a benefit of insulin aspart.

The long-term results (check-up 4) are more encouraging than the results from the first 80-day period (checkup 3) where no improvement of HbAlc could be seen. Nevertheless, our results from check-up 3 correspond to the results of the multicenter randomized parallel-group study of Bode et al. (1) comparing the differences between insulin aspart, buffered regular insulin and insulin lispro: 146 adult patients were randomized and no differences in HbAlc concentrations could be found within a 16 weeks period of insulin pump treatment.

There was only a small difference between the P-glucose profiles with Velosulin HM and with Novorapid. In intensive conventional insulin treatment the effects of Novorapid on postprandial P-glucose concentrations are emphasized ${ }^{7,14}$. In continuous subcutaneous insulin treatment with intensive selfmonitoring, however, the correct basal rate and prandial boluses may better prevent the development of postprandial hyperglycaemia either with Velosulin HM or with Novorapid. It must be also taken into consideration that the timing of P-glucose measurements in ten-point selfmonitoring profiles was not absolutely precise. The patient is often known to get the best results before a check-up. Nevertheless, even though there is little statistical significance between P-glucose profiles (probably due to the methodical factors mentioned), the decisive parameters to assess the effectiveness of insulin treatment are $\mathrm{HbA1c}$, daily insulin dose and BMI.

\section{CONCLUSIONS}

In persons with the type 1 diabetes mellitus treated by an insulin pump, the benefits of insulin aspart (Novorapid) on metabolism of carbohydrates was demonstrated: despite the lower daily dose of insulin aspart (Novorapid) vs phosphate buffered human regular insulin (Velosulin $\mathrm{HM})$, the HbA1c decreased. The frequency of hypo- and hyperglycaemia, the BMI, blood pressure and heart rate did not change. No significant influence of insulin aspart on selected parameters of liver or kidney functions and no other side effects were found. Patients' satisfaction with Novorapid was good. Hence, insulin aspart (Novorapid) appears to be more effective for continuous insulin infusion than phosphate buffered regular human insulin (Velosulin HM) and may be recommended.

\section{REFERENCES}

1. Bode B, Raskin P, Weinstein R, Davidson J, Bell D, Henry R, McGill J, Huang WC, Nadeau D, Reinhardt RR. (2002) Comparison of insulin aspart with buffered regular insulin and insulin lispro in continuous subcutaneous insulin infusion - A randomized study in type 1 diabetes. Diabetes Care 25, 439-444.

2. Bode BW, Strange P. (2001) Efficacy, safety, and pump compatibility of insulin aspart used in continuous subcutaneous insulin infusion therapy in patients with type 1 diabetes. Diabetes Care 24, 69-72.

3. Home PD, Lindholm A, Hylleberg B, Round P. (1998) Improved Glycemic Control With Insulin Aspart. Diabeties Care 21, 19041909.

4. Heller S (2002) Reducing hypoglycamia with insulin analogues. Int. J. Obes. 26, S31-S36.

5. Chapman TM, Noble S, Goa KL. (2002) Insulin aspart, A review of its use in the management of type 1 and 2 diabetes mellitus. Drugs 62, 1945-1981.

6. Lindholm A, Jacobsen LV. (2001) Clinical pharmacokinetics and pharmacodynamics of insulin aspart. Clin Pharmacokinet 40, 641-659.

7. Lindholm A, McEwen J, Riis AP. (1999) Improved Postprandial Glycemic Control With Insulin Aspart. Diabetes Care 22, 801-805.

8. Mach MA, Brinkmann C, Hansen T, Weilemann LS, Beyer J. (2002) Differences in pharmacokinetics and pharmacodynamics of insulin lispro and aspart in healthy volunteers. Exp Clin Endocrinol Diabetes 110, 416-419. 
9. Melki V, Belicar P, Renard E, Jeandidier N, Lassmann-Vague V, Meyer L, Boivin S, Blin P, Guerci B, Augendre-Ferrante B, HanaireBroutin H, Tauber JP, Bringer J. (1998) Improvement of $\mathrm{HbA}(1 \mathrm{c})$ and blood glucose stability in IDDM patients treated with lispro insulin analog in external pumps. Diabetes Care 21, 977-982.

10. Pickup JC, Keen H, Parsons JA, Alberti KGMM. (1978) Continuous subcutaneous insulin infusion: an approach to achieving normoglycaemia. Brit Med J 1, 204-207.

11. Plank J, Wutte A, Brunner G, Siebenhofer A, Semlitsch B, Sommer R, Hirschberger S, Pieber TR. (2002) A Direct Comparison of
Insulin Aspart and Insulin Lispro in Patients With Type 1 Diabetes. Diabetes Care 25, 2053-2057.

12. Renner R, Pfutzner A, Trautmann M, Harzer O, Sauter K, Landgraf R. (1999) Use of insulin lispro in continuous subcutaneous insulin infusion treatment. Result of a multicenter trial. German HumalogCSII Study Group. Diabetes Care 22, 784-8.

13. Standl E. (2002) Insulin analogues - State of the art. Horm Res $57,40-45$.

14. Walter M, Ziegler AG, Achenbach P. (2003) TrialNet - ein internationales Netwerk für die Erforschung neuer Therapie des Typ-1Diabetes. Diabetes und Stoffwechsel 12, 263-268. 